\title{
Posterior reversible encephalopathy syndrome: Some novel associations
}

\author{
M Nandi, ${ }^{1}$ MD; S Sarkar, ${ }^{2} \mathrm{MD}$; R Mondal, ${ }^{3} \mathrm{MD}$; T Dhibar, ${ }^{4} \mathrm{MD}$ \\ ${ }^{1}$ Pediatrics, Nil Ratan Sircar Medical College, Kolkata, India \\ ${ }^{2}$ Pediatrics, Institute of Post-Graduate Medical Education and Research, Kolkata, India \\ ${ }^{3}$ Medical College, Kolkata, India \\ ${ }^{4}$ Department of Neuroradiology, Bangur Institute of Neurosciences, Kolkata, India
}

Corresponding author: M Nandi (madhumitabanik@rediffmail.com)

\begin{abstract}
Posterior reversible encephalopathy syndrome (PRES) (also called reversible posterior leukoencephalopathy syndrome) is a mostly transient and reversible neurological disorder clinically characterised by headache, seizures, blindness and altered consciousness associated with radiological abnormalities in the posterior white matter. Hypertension has been implicated as the most common association. We report four cases of PRES associated with non-hypertensive causes together with a review of the literature. Two cases occurred following cerebral anoxia due to accidental strangulation and near-drowning, respectively. The third patient, a child known to have E- $\beta$ thalassaemia, presented with transient encephalopathy following blood transfusion but involving the anterior brain rather than the posterior part classically described in PRES. The fourth patient developed PRES while recovering from toxic epidermal necrolysis syndrome. None of these four cases had hypertension at any point during their illness.
\end{abstract}

S Afr J Child Health 2015;9(4):137-139. DOI:10.7196/SAJCH.2015.v9i4.934

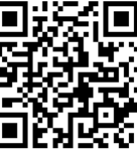

Posterior reversible encephalopathy syndrome (PRES) is characterised by the acute onset of transient and usually reversible alteration of consciousness, seizures, headache and visual disorders, and is associated with abnormal neuroimaging findings mostly in the parieto-occipital cortex. ${ }^{[1]}$ We describe four children with PRES with novel aetiological associations. The first two had hypoxia following accidental strangulation and near-drowning, respectively. The third, a thalassaemic child receiving regular blood transfusions, had PRES following one such transfusion episode. The fourth child had PRES while recovering from toxic epidermal necrolysis syndrome (TENS). In addition, the child with thalassaemia had involvement of the anterior brain instead of the classically described posterior parts of the brain.

\section{Case reports}

Key features of the four cases are detailed in Table 1. PRES in cases 1 and 2 appears to have been precipitated by brain hypoxia, as a result of strangulation and drowning, respectively. The third child was on regular blood transfusions and PRES occurred following one such blood transfusion. The neuroradiological findings of the third child differed as she had involvement of the anterior brain rather than the more commonly reported posterior brain. The fourth child was admitted initially with a diagnosis of TENS. She had $80 \%$ involvement of the body surface area along with oral, genital and conjunctival mucosal lesions. Hence, her SCORTEN score ${ }^{[2]}$ was 4 , giving her mortality risk of $58.3 \%$. She also developed septicaemia with blood culture growing Acinetobacter baumanii sensitive to colistin. She was on the road to recovery, having responded to intensive supportive care and IV antibiotics, when she developed features of PRES on day 12 of admission.

\section{Discussion}

PRES (also termed reversible posterior leukoencephalopathy syndrome), first described in 1996, is a neurological disorder clinically characterised by headache, seizures, blindness and altered consciousness associated with radiological features of oedema, most often involving the white matter in the posterior regions of the cerebral hemispheres. The oedema is often more pronounced bilaterally in the parieto-occipital regions, but may sometimes spread to the basal ganglia, brainstem and cerebellum. The oedema is usually completely reversible with resolution of clinical symptoms and radiological features. This is in contrast to changes resulting from hypoxicischaemic insults, which show permanent radiological signs. PRES was first reported by Hinchey et al. ${ }^{[1]}$ in 1996 after an observational study of 15 patients. Since then, a few case reports and some case series have been published. ${ }^{[3-6]}$

The most frequently implicated cause of PRES is a hypertensive crisis. Renal failure, fluid retention, and some immunosuppressive drugs have also been reported as causes. ${ }^{[4]}$ Despite an extensive search, we could not find any aetiological association of PRES with strangulation, drowning, red cell transfusion for thalassaemia or TENS.

The exact pathophysiology of PRES has yet to be elucidated. It has been postulated that the clinical features might be due to sudden disruption of the autoregulatory mechanisms of the central nervous system vasculature, resulting in endothelial dysfunction and breakdown of the blood-brain barrier. Sudden elevation of blood pressure could be one of the factors leading to this disruption. There is a predilection for involvement of posterior circulation territories, thought to result from the relatively sparse sympathetic innervations of the vertebrobasilar circulation, but there are reports of involvement of the anterior brain, brainstem, basal ganglia, corpus callosum and cerebellum (atypical magnetic resonance imaging (MRI) findings). ${ }^{[1,6]}$ The second postulated cause for PRES is a direct cytotoxic effect on the cerebrovasular endothelium. ${ }^{[6]}$

We report these cases to highlight some unusual associations with this condition. The first two cases are unique as the patients had PRES following hypoxic encephalopathy. The third patient did not have any overt cerebral anoxia but had received a blood transfusion preceding this event. There are a few case series and some reports of PRES occurring after blood transfusion, ${ }^{[7-10]}$ but none associated with E- $\beta$ thalassaemia or with involvement of anterior regions of the brain. We suspect that a rapid transfusion may have been responsible for PRES in this case. Rapid transfusion can result in a sudden rise in total blood volume, resulting in rapid increase in cerebral blood flow. Such acutely induced cerebral hyperperfusion could exceed the capacity for cerebral autoregulation and produce vasogenic oedema 
Table 1. Details of the patients with PRES

\begin{tabular}{|c|c|c|c|c|}
\hline & Patient 1 & Patient 2 & Patient 3 & Patient 4 \\
\hline Age & 7 months & 3 years & 5 years & 4 years \\
\hline Gender & Female & Male & Female & Female \\
\hline Brief history & $\begin{array}{l}\text { Deep unconsciousness } \\
\text { following accidental } \\
\text { strangulation as a result } \\
\text { of getting accidentally } \\
\text { stuck between the wall } \\
\text { and the side of her bed, } \\
\text { compressing her neck }\end{array}$ & $\begin{array}{l}\text { Unconsciousness and } \\
\text { generalised convulsions } \\
\text { following near- } \\
\text { drowning in a local pool }\end{array}$ & $\begin{array}{l}\text { Vomiting, severe headache, } \\
\text { aphasia and drowsiness } 2 \\
\text { days after receiving two } \\
\text { units of packed cells in } \\
\text { a known case of E- } \beta \text { - } \\
\text { thalassaemia }\end{array}$ & $\begin{array}{l}\text { Generalised maculopapular } \\
\text { and bullous eruptions following } \\
\text { ingestion of some antipyretics with } \\
\text { involvement of oral, genital and } \\
\text { conjunctival mucosa. Developed } \\
\text { sudden-onset focal convulsion } \\
\text { with secondary generalisation } \\
\text { followed by headache and loss of } \\
\text { vision on D12 }\end{array}$ \\
\hline
\end{tabular}

admission

$\begin{array}{lll}\text { Pulse rate }(/ \mathrm{min}) & 130 & 108 \\ \text { Respiratory rate }(/ \mathrm{min}) & 30 & 36 \\ \text { Blood pressure }(\mathrm{mmHg}) & 70 / 46 & 76 / 50 \\ \text { GCS } & \text { E1V1M1 } & \text { E1V2M1 } \\ \text { Others } & \begin{array}{l}\text { Pupils bilaterally dilated } \\ \text { and responding sluggishly }\end{array} & \begin{array}{l}\text { Pupils bilaterally dilated } \\ \text { and non-reacting }\end{array}\end{array}$

$90 \quad 100$

$22 \quad 24$

$92 / 60 \quad 90 / 58$

E3V4M5 E4V4M4

Pupils normal, liver $4 \mathrm{~cm}, \quad$ Pupils dilated and reacting spleen $5 \mathrm{~cm} \quad$ sluggishly (all features were at onset of neurological manifestations)

\section{Investigations}

\begin{abstract}
$\mathrm{Hb}(\mathrm{g} / \mathrm{dL})$
$\mathrm{TC}\left(/ \mathrm{mm}^{3}\right)$

DC

Platelets $\left(\mathrm{lac} / \mathrm{mm}^{3}\right)$

Serum electrolytes, calcium, creatinine blood sugar

Chest X-ray

CSF study
\end{abstract}

Management given

Time to regain

consciousness (days)

Condition on discharge

Time for full recovery

MRI findings during the acute stage
13400

N-56, L-45

1.6

Within normal range

Patchy opacities

No abnormality

$\mathrm{ABC}$ of resuscitation, mechanical ventilation for 10 days, mannitol for 4 days

10

Fully conscious and breastfeeding

One month. Achieved normal milestones of development

Bilateral extensive and confluent hyperintensities in the white matter, mostly in the parietal and occipital lobe, suggestive of PRES
10.4

11300

N-68, L-32

1.8

Within normal range

Normal

No abnormality

$\mathrm{ABC}$ of resuscitation, mechanical ventilation for 5 days, mannitol for 3 days

6

Conscious, orientated, seizure free but unable to see

Vision gradually improved for 2 months

Hyperintense signals in both parieto-occipital regions with mild diffusion restriction in $\mathrm{T} 2$ and flair images (Fig. 1a)
9.6

9600

N-64, L-26

2.2

Within normal range

Normal

No abnormality

IV fluids and mannitol

4

Fully conscious

Regained speech gradually and recovered completely neurologically by 2 months

Multiple hyperintense lesions over subcortical white matter involving cerebral and cerebellar regions in $\mathrm{T} 2$ and flair image
9.8

6440

N-78, L-22

2.5

Within normal range

Normal

No abnormality

IV fluids, methylprednisolone during the TENs stage,

IV fluids and mechanical ventilation for 4 days after neurological manifestations 7

Fully conscious

Gradual improvement in vision over 3 months

Bilateral hyperintensities in both parietal and occipital lobes 
Table 1 (continued). Details of the patients with PRES

\begin{tabular}{|c|c|c|c|c|}
\hline & Patient 1 & Patient 2 & Patient 3 & Patient 4 \\
\hline $\begin{array}{l}\text { MRI findings after } \\
\text { recovery ( } 6 \text { months after } \\
\text { acute episode) }\end{array}$ & No abnormality & $\begin{array}{l}\text { Complete disappearance } \\
\text { of hyperintensities } \\
\text { (Fig. 1b) }\end{array}$ & $\begin{array}{l}\text { No abnormality. Complete } \\
\text { disappearance of } \\
\text { hyperintensities }\end{array}$ & $\begin{array}{l}\text { Complete recovery. No residual } \\
\text { abnormality }\end{array}$ \\
\hline Final diagnosis & $\begin{array}{l}\text { PRES due to accidental } \\
\text { strangulation }\end{array}$ & $\begin{array}{l}\text { PRES due to near- } \\
\text { drowning }\end{array}$ & $\begin{array}{l}\text { PRES following red cell } \\
\text { transfusion in a child with } \\
\text { thalassaemia }\end{array}$ & PRES following TENS \\
\hline
\end{tabular}

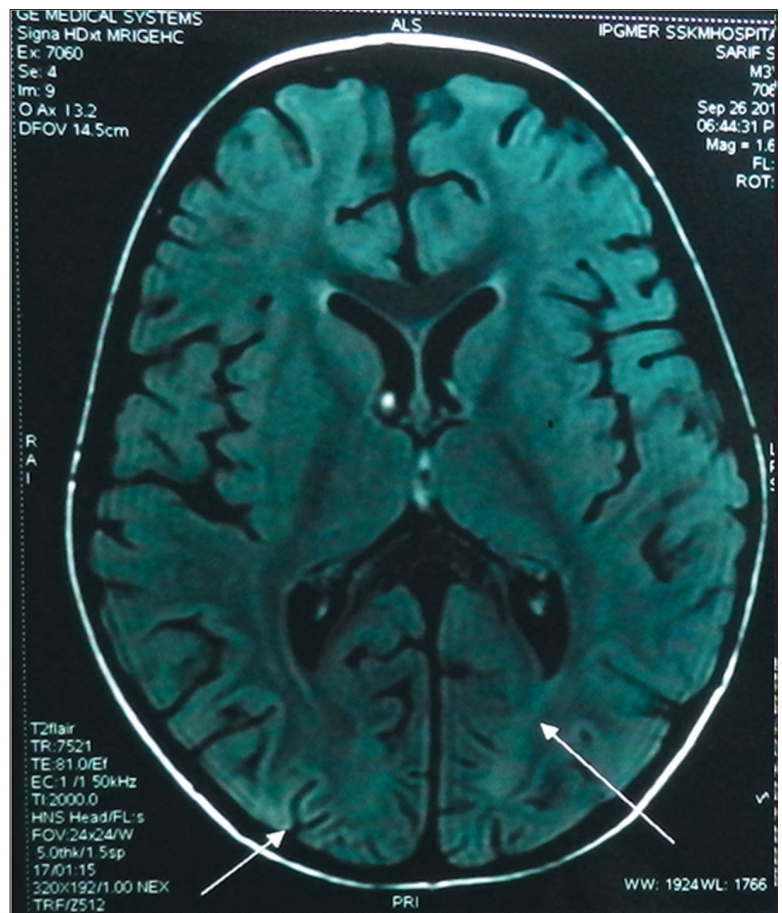

Fig. 1a. Hyperintense signals in both parieto-occipital regions with mild diffusion restriction in T2 flair images of patient 2 (PRES due to near-drowning).

leading to PRES. ${ }^{[10]}$ The fourth child had PRES while recovering from TENS. The pathophysiology behind PRES with TENS remains unknown.

Although hypertension has been implicated as the most common aetiology of PRES, blood pressure was not raised at any time during the course of illness in any of these cases.

The importance of these cases lies in the fact that although PRES is a serious life-threatening condition, it is almost always completely reversible if appropriate management is given in the acute stage. Also, given the scores of patients given blood transfusion for thalassaemia in our regular practice, more vigilance and awareness may pick up many similar cases. Early recognition of characteristic radiological features is key to the diagnosis as clinical symptoms may be nonspecific or mimic other more common neurological illnesses.

Only long-term multicentre follow-up studies will provide more clues regarding the exact pathogenesis and non-hypertensive etiological factors involved in this condition, especially in children, in whom the physiology of cerebral circulation may be different from that of adults.

\section{References}

1. Hinchey J, Chaves C, Appignani B, et al. A reversible leuoencephalopathy syndrome. N Engl Med J 1996;334(8):494-500. [http://dx.doi.org/10.1056/ NEJM199602223340803]

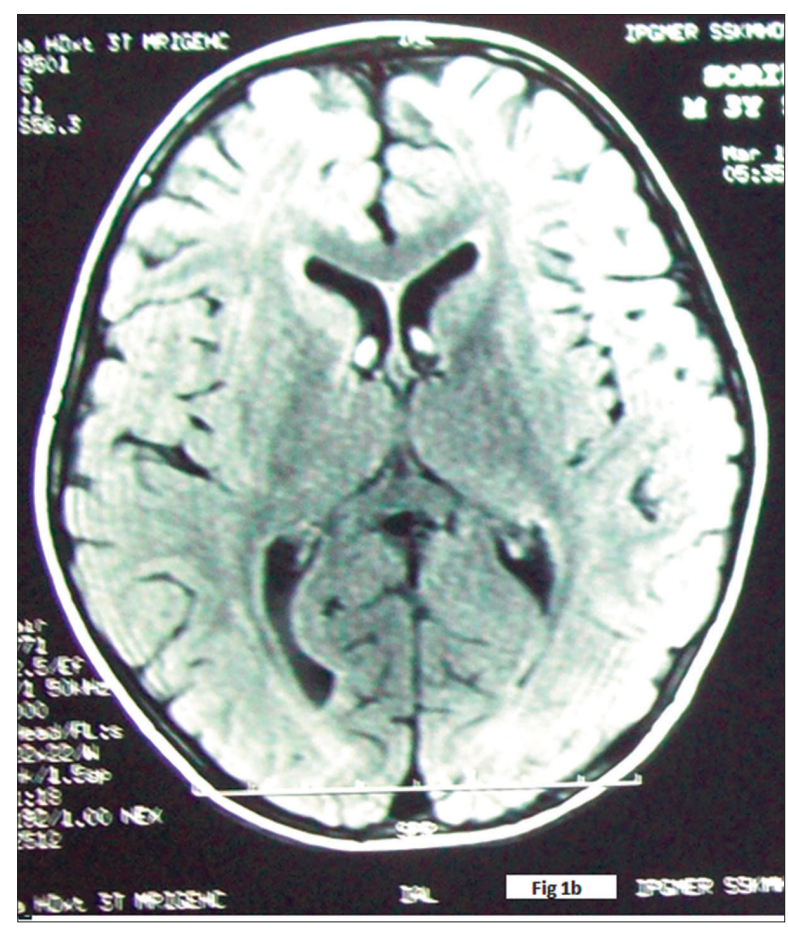

Fig. 1b. Complete disappearance of the hyperintensities after 6 months.

2. Bastuji-Garin S, Fouchard N, Bertocchi M, Roujeau JC, Revuz J, Wolkenstein P. SCORTEN: A severity-of-illness score for toxic epidermal necrolysis. J Invest Dermatol2000;115(2):149-153. [http://dx.doi.org/10.1046/j.1523-1747.2000.00061.x]

3. Moratalla MB. Posterior reversible encephalopathy syndrome. Emerg Med J 2010;27(7):547. [http://dx.doi.org/10.1136/emj.2008.069765]

4. Incecik F, Herguner MO, Altunbasak S, Erbey F, Leblebisatan G. Evaluation of nine children with reversible posterior encephalopathy syndrome. Neurol India 2009;57(4):475-478. [http://dx.doi.org/10.4103/0028-3886.55605]

5. Endo A, Fuchigami T, Hasegawa M. Posterior reversible encephalopathy syndrome in childhood: Report of four cases and review of the literature. Pediatr Emerg Care 2012;28(2):153-157. [http://dx.doi.org/10.1097/ PEC.0b013e3182442fe8]

6. Chen TH, Lin WC, Tseng YH, Tseng CM, Chang TT, Lin TJ. Posterior reversible encephalopathy syndrome in children: Case series and systematic review. J Child Neurol 2013;28(11):1378-1386. [http://dx.doi.org/10.1177/0883073813500714]

7. Huang YC, Tsai PL, Yeh JH, Chen WH. Reversible posterior leukoencephalopathy syndrome caused by blood transfusion: A case report. Acta Neurol Taiwan 2008;17(4):258-262.

8. Khademian Z, Speller-Brown B, Nouraie SM, Minniti CP. Reversible posterior leuko-encephalopathy in children with sickle cell disease. Pediatr Blood Cancer 2009;52(3):373-375. [http://dx.doi.org/10.1002/pbc.21812]

9. Kolovou V, Zampakis P, Ginopoulou A, Varvarigou A, Kaleyias J. Reversible posterior leukoencephalopathy syndrome after blood transfusion in a pediatric patient with sickle cell disease. Pediatr Neurol 2013;49(3):213-217. [http:// dx.doi.org/10.1016/j.pediatrneurol.2013.04.024]

10. Wada K, Kano M, Machida Y, Hattori N, Miwa KH. Posterior reversible encephalopathy syndrome induced after blood transfusion for severe anemia. Case Reports Clin Med 2013;2(5):332-334. [http://dx.doiorg/10.4236/ crcm.2013.25089] 